\title{
Knowledge and utilization of colorectal cancer screening in Saudi society
}

\section{Sharifah Othman ${ }^{1}$, Faten Alaqeel ${ }^{2}$, Eiman AlShammari ${ }^{1}$, and Rana Fallatah ${ }^{2}$}

1. College of medicine, Imam Abdulrahman bin Faisal University King Fahad University Hospital, Khobar,

Kingdom of Saudi Arabia

2. General surgery department, Imam Abdulrahman bin Faisal University King Fahad University Hospital,

Khobar, Kingdom of Saudi Arabia

\section{RESEARCH}

Please cite this paper as: Othman S, Alaqeel F, AlShammari $\mathrm{E}$, Fallatah R. Knowledge and utilization of colorectal cancer screening in Saudi society. AMJ 2019;12(12):368-375. https://doi.org/10.35841/1836-1935.12.12.368-375

\section{Corresponding Author:}

Sharifah Othman

College of medicine, Imam Abdulrahman bin Faisal University King Fahad University Hospital, Khobar, Kingdom of Saudi Arabia

Email: othmansag@hotmail.com

\section{ABSTRACT}

\section{Background}

In Saudi Arabia (SA), cancer is a major burden on the healthcare system. It has a great impact on both the social and economic aspects of the patient. The Saudi cancer registry reports an increase in the incidence of all cancers since the first report in 1994. Colorectal Cancer (CRC) is the most common type of cancer in SA.

\section{Aims}

To measure the utilization and the knowledge of Saudi population about screening for CRC and the awareness of the society towards CRC incidence and risk factors.

\section{Methods}

A questionnaire-based cross-sectional survey was conducted with simple random sampling of 636 individuals between February 2018 to May 2018. The questionnaire comprised of 19 questions covering personal data of the participant, degree of awareness about colorectal cancer in Saudi Arabia, and information about colonoscopy and how it's done.
Results

The known risk factors for $\mathrm{CRC}$, that are inflammatory bowel disease (IBD), smoking and polyps, were recognized by less than 50 per cent of the respondents. Almost two thirds of the respondents were willing to do screening. Willingness to do screening was significantly associated with a history of colonoscopy for the respondent or a relative.

\section{Conclusion}

The knowledge and awareness of our sample about CRC was low. Raising the level of knowledge is anticipated to increase the readiness to do screening.

\section{Key Words}

Colorectal cancer, knowledge, screening, attitude

\section{What this study adds:}

\section{What is known about this subject?}

The prevalence of colorectal cancer (CRC) is high among different countries, being higher in North America, Australia, and Northern and Western Europe. In contrast, developing countries, especially in Africa and Asia, have lower rates. CRC rarely occurs before the age of 40 years and is common at the age of $40-50$ years.

\section{What new information is offered in this study?}

The knowledge and awareness of our sample about CRC was low. Raising the level of knowledge is anticipated to increase the readiness to do screening.

3. What are the implications for research, policy, or practice?

The present data may be useful as a fundamental data in making health policy in this area toward management and prevention of CRC.

\section{Background}

The prevalence of colorectal cancer (CRC) is high among different countries, being higher in North America, 
Australia, and Northern and Western Europe. In contrast, developing countries, especially in Africa and Asia, have lower rates. CRC rarely occurs before the age of 40 years and is common at the age of $40-50$ years. ${ }^{1}$

In Saudi Arabia (SA), cancer is a major burden on the healthcare system. It has a great impact on both the social and economic aspects of the patient. The Saudi cancer registry reports an increase in the incidence of all cancers since the first report in $1994 .^{2}$

CRC is the most common type of cancer in SA. Studies have shown that CRC presents at a younger age in SA than in western counties and this calls for lowering of the screening age to 45 years in healthy individuals. ${ }^{2}$ In SA, CRC was the most common form of cancer in men and the third most common in women between 1994 and 2004. ${ }^{2,3}$ By 2014, according to the Saudi cancer registry, it became the second most common among women aged $45-74$ years. ${ }^{2}$

In such cases, screening is important for the early detection of CRC in the precancerous stage and prevention of further complications or development into the advanced stage. Screening at a proper age is important for prevention and control, and further, it is considered cost-effective. ${ }^{4}$ It is anticipated that a policy of screening for CRC will decrease the burden on the government and improve the health of the Saudi population.

There are many tests available for the detection of CRC. These include annual faecal immunochemical test (FITs) and guaiac-based faecal occult blood test (gFOBTs), and stool DNA tests every three years. These tests can be performed routinely before the age of 50 years, especially in high-risk patients who have a personal history of CRC or adenomatous polyps, inflammatory bowel disease (IBD), or a strong family history of colorectal cancer or familial adenomatous polyposis. ${ }^{5}$

The gold standard for CRC screening is colonoscopy since it is highly effective. In SA, screening for CRC is recommended at the age of 45 years for asymptomatic individuals who are at average risk. In most cases, screening is not recommended for individuals above 70 years. However, colonoscopy is the only modality that is recommended every 10 years, followed by FS every five years and gFOBT or FIT every year, if colonoscopy is unavailable. All these screening procedures should be performed by highly skilled and experienced staff in well-equipped medical centers. ${ }^{4}$

The aim of this study was to measure the utilization and the knowledge of CRC screening in the Saudi population, to investigate the awareness of CRC incidence and risk factors in the society, and to emphasize the importance of screening and early prevention among the population by establishing an effective educational program.

\section{Method}

\section{Study design and data collection instrument:}

This cross-sectional study was conducted with 636 individuals living in different area in Saudi Arabia, using simple random sampling, who were approached to participate in CRC questionnaire after obtaining verbal informed consent, between February 2018 to May 2018. The questionnaire was comprised of 19 questions gradually moving from personal data of the participant, degree of awareness about colorectal cancer in Saudi Arabia and screening, to her/his information about colonoscopy and how it's done. All questions were in Arabic and in multiple choice format. For analyses, age was grouped as follows: 25 or less, 26-45, 46 or more. Also, educational level was grouped as intermediate school or below, secondary school, bachelor's degree, master degree or above.

\section{Ethics considerations:}

The study protocol was approved by the ethics review board of Imam Abdulrahman bin Faisal University, Dammam.

\section{Statistical methods:}

An excel spreadsheet was established for data entry. Data analysis was carried out using SPSS version 22. Categorical variables were summarized as frequencies and percentages, and the association between variables was tested using Pearson's Chi-square or Fisher-Freeman-Halton Exact Tests, as appropriate. A p-value of $<0.05$ was considered statistically significant.

\section{Results}

A total of 636 participants responded to the questionnaire. Table 1 shows the characteristics of the respondents, their utilization of CRC screening, and the knowledge of respondents about the ranking of $\mathrm{CRC}$, age at risk, risk factors, and awareness of screening programs. The highest frequency of respondents belonged to the age groups $26-$ 45 years ( 50.3 per cent), 25 years or less (27.4 per cent), and 46 years or more (22.3 per cent). Women outnumbered men (75.5 per cent vs. 24.5 per cent). The majority of respondents were from Saudi (97.3 per cent) and did not have a family history of CRC (82.4 per cent). For those with a family history, 45 per cent were fourth-degree relatives, followed by 22.2 per cent with third-degree relatives. The relative was diagnosed with CRC at the age of 40-59 years 
old in 46.5 per cent of the cases and at the age of 60 years or above in 32.7 per cent of cases, with a median age of 50 years. Only 10.2 per cent of the respondents had undergone colonoscopy before. Only 34.4 per cent were aware of how colonoscopy was done. Regarding the ranking of CRC among men in SA, 45.3 per cent of respondents believed it to be the second most common among all cancers, 32.5 per cent believed it to be the third, and 22.2 per cent thought it to be the most common. As for women in SA, some respondents ranked it the third most common (46.5 per cent), whereas others ranked it second (40.7 per cent) and first (12.7 per cent). More than half (50.3 per cent) of the respondents thought that no screening program for CRC was available in SA.

The optimum age for screening in healthy individuals was $35,40,45$, and 50 years old according to 48.9 per cent, 29.2 per cent, 8.8 per cent, and 6.4 per cent of the respondents, respectively, whereas 6.6 per cent thought that there was no need for screening. The age for screening in high-risk patients was $30,35,40$, and 45 years old according to 71.9 per cent, 16.4 per cent, 10.2 per cent, and 1.6 per cent of the respondents, respectively. Most respondents understood that PE examination is not enough to detect CRC (91.8 per cent). The risk factors for CRC that were most recognized by the respondents were family history (56 per cent), IBD (48.7 per cent), smoking (39.2 per cent), intestinal polyps (35.8 per cent), and obesity (22.5 per cent).

Figure (1) reveals that the respondents' answers about CRC ranking in SA and appropriate age for screening were mostly incorrect, except for the age for screening in high-risk persons, as 88.2 per cent of the respondents correctly identified the recommended age.

Figure (2) illustrates that most respondents (76.4 per cent) stated they were willing to undergo screening for CRC. We then proceeded to identify the factors that were significantly associated with willingness to undergo screening for CRC.

Tables 2 show that willingness to undergo screening was significantly associated with a history of colonoscopy in the respondent $(p=0.016)$ or a relative $(p=0.006)$.

In our study, there was a lack of association between family history of CRC and willingness to undergo screening, with a percentage of 27.5 per cent for those with a positive family history and refusing screening.

\section{Discussion}

Colorectal cancer represents a major health problem in SA as it occupies the first rank among cancers affecting men and the second among cancers affecting women in SA. ${ }^{2}$ Regular screening that starts at an appropriate age is mandatory for early detection of CRC, early management, and better prognosis. ${ }^{6,7}$

Screening depends on the awareness of the public, particularly individuals at high risk, about the magnitude of the CRC problem, its risk factors, and the benefits that can be gained through screening, ${ }^{8-10}$ as well as their willingness to undergo screening. Therefore, the aim of this study was to measure the utilization and the knowledge of screening for CRC among the Saudi population, to investigate the awareness in the society towards CRC incidence and risk factors, and to emphasize the importance of screening and early prevention among the population by establishing an effective educational program.

Our results revealed that the respondents' level of awareness and knowledge about CRC prevalence, risk factors, and screening was poor and inadequate. Many studies have reported similar results in different countries including SA, ${ }^{11-16}$ Greece, ${ }^{17}$ Australia, ${ }^{18}$ Iran, $^{19}$ and Spain. ${ }^{9}$

With regards to the prevalence of CRC among the Saudi population, only 22.2 per cent of the respondents correctly placed it as the most common in men, while the remaining undermined its magnitude by assigning it the second and third ranks. The prevalence among Saudi women was better recognized as 40.7 per cent of the respondents assigned it the second rank. This lack of awareness about the prevalence of CRC in SA could result in undermining the importance of screening among the public as they consider the disease less prevalent, and consequently, believe the risk of being affected by CRC is lower than that for other cancers.

The known risk factors for CRC, which include IBD, smoking, and polyps, were recognized by less than 50 per cent of the respondents. Family history of CRC was the most widely recognized (56 per cent of respondents) risk factor. The least identified risk factor was obesity (22.5 per cent). This poor knowledge about risk factors was revealed by other studies too. Al Wutayd et al. ${ }^{15}$ stated that less than one-fifth (18 per cent) of the respondents correctly identified colorectal polyps as a risk factor. Moreover, Zubaidi et al. ${ }^{14}$ conducted a survey in Riyadh, SA and found a poor level of knowledge about risk factors of CRC since polyps were identified by less than 20 per cent while a family history of 
CRC was known only to 34.8 per cent of the surveyed individuals. Galal et al. ${ }^{11}$ conducted a study in Al Hassa governorate, SA and found that about one-third knew that obesity is a risk factor. Similarly, Al Eid et al. ${ }^{12}$ stated that 49 per cent of the respondents knew about the risk factors of CRC such as obesity and smoking.

As the prevalence of CRC in SA is high, there is a need for establishing a national screening program to ensure early detection in patients. The aim of screening is to identify patients at risk by early detection of precancerous lesions and small cancers before they become advanced and unsuitable for treatment. In SA, clinical practice guidelines for CRC have been published. ${ }^{4}$ However, there is no national policy for CRC screening despite increasing disease incidence. ${ }^{12,20}$ Moreover, due to lack of knowledge, the Saudi population is less likely to undergo screening for CRC than for other screening-amenable tumours, such as breast and cervical cancer. ${ }^{21}$ More than half (50.3 per cent) the respondents were unaware that the screening program for CRC was available in SA.

The vast majority of our respondents knew that PE examination is not enough to detect CRC. This is a positive aspect suggesting that respondents were willing to accept the concept and perceive the role of screening tests. Almost two-thirds of the respondents were willing to undergo screening. This finding is in agreement with results from Almadi et al. ${ }^{13}$ who conducted a public survey in Riyadh, SA and found that approximately 70.7 per cent were willing to undergo a screening test for CRC. Moreover, Gimeno-Garcia et al. ${ }^{9}$ studied public awareness of CRC and screening in a Spanish population and reported that 78.8 per cent of the subjects were willing to participate in CRC screening.

Colonoscopy is the gold standard for CRC screening. However, only one-third of our respondents knew how colonoscopy is performed. Ignorance among the general public about colonoscopy can negatively affect their willingness to undergo the procedure. The perception of colonoscopy being painful was found to be high even among fourth-year Greek medical students, as 57 per cent thought it was painful and 85 per cent preferred an alternative method to colonoscopy for CRC screening. ${ }^{17}$ Therefore, details about the indication, benefits, and hazards of colonoscopy should be included in the health education programs that focus on CRC screening.

Screening for CRC in asymptomatic individuals who are at average risk is recommended in SA. The American cancer society recommends colonoscopy in the normal population from age 50 and for at-risk patients, 10 years earlier than the age of the affected patient. ${ }^{22}$ However, the national guidelines of SA recommend lowering the age to 45 years for individuals at average risk and even further for those at high risk. ${ }^{4}$ This recommendation was based on reports of increased incidence of CRC in young individuals from Saudi presenting with a more advanced stage of the disease. . $^{43,24}$ The proper age for the screening of CRC in healthy individuals was incorrectly perceived by most respondents; responses tended to recommend lower than 45 years of age. Meanwhile, the recommended age for screening in individuals at high risk was correctly identified by a majority of the respondents. This confusion regarding the proper age for screening was reported by Al Eid et al. ${ }^{12}$ in Alahsa, SA.

In the present study, willingness to undergo screening was significantly associated with a history of colonoscopy in the respondent or a relative. These findings emphasize the importance of raising awareness and providing health education about the colonoscopy procedure and the risk factors of CRC. Nevertheless, 17.6 per cent of our respondents had a positive family history for CRC. Unexpectedly, and contradictory to known literature, there was a higher, though insignificant, percentage of screening refusals among those with a positive family history. This finding is hard to explain and needs more exploration by further studies, to determine if it is a genuine difference present in the Saudi population or a false impression caused by the low percentage of respondents reporting family history.

The median age of family members when diagnosed with CRC was 50 years, with 46.5 per cent of relatives being diagnosed at an age ranging from 40-59 years. This age is comparable to that reported by studies conducted worldwide and in SA. The likelihood of CRC diagnosis increases after the age of 40 and rises sharply after the age of $50 .{ }^{25,26}$ Mosli and Al-Ahwal $^{3}$ found that the mean age of patients at the time of diagnosis was 58 years and most patients were above 45 years of age.

Other studies have reported a positive effect of family history on the willingness to undergo screening. Almadi et al. ${ }^{13}$ reported that the percentage of individuals willing to undergo screening increased to 83 per cent in those who had a family history of CRC. Moreover, family history was found to increase the readiness to undergo screening in a study by Galal et al. ${ }^{11}$ This positive effect of family history may be attributed to a perceived increased risk of the disease or better knowledge about the disease and the importance of screening, as family history was associated 
with better knowledge of CRC. ${ }^{15,27,28}$

\section{Conclusion}

The knowledge and awareness of CRC were low in our sample population. It is expected that raising the level of knowledge will increase the willingness to undergo screening. Therefore, educational health programs should be initiated to inform the general public, particularly the atrisk groups, about the prevalence of CRC in SA, its risk factors, the benefits of screening and its impact on the prognosis of patients, and screening methods.

\section{References}

1. Eddy DM. Screening for colorectal cancer. Ann Intern Med. 1990;113:373-84.

2. Saudi Cancer Registry. Cancer incidence report 2014. Riyadh, Saudi Arabia: Saudi Health Council, 2014. https://nhic.gov.sa/eServices/Documents/2014.pdf

3. Mosli MH, Al-Ahwal MS. Colorectal cancer in the Kingdom of Saudi Arabia: need for screening. Asian Pac J Cancer Prev. 2012;13(8):3809-13.

4. Alsanea N, Almadi MA, Abduljabbar AS, et al. National guidelines for colorectal cancer screening in Saudi Arabia with strength of recommendations and quality of evidence. Ann Saudi Med. 2015;35(3):189-95.

5. American Cancer Society. Colorectal Cancer Risk Factors 2018 [cited 2018 2/12/2018]. Available from: https://www.cancer.org/content/cancer/en/cancer/col on-rectal-cancer/causes-risks-prevention/riskfactors.html

6. Garborg K, Holme O, Loberg M, et al. Current status of screening for colorectal cancer. Ann Oncol. 2013;24(8):1963-72.

7. Levin B, Lieberman DA, McFarland B, et al. Screening and surveillance for the early detection of colorectal cancer and adenomatous polyps, 2008: a joint guideline from the American Cancer Society, the US Multi-Society Task Force on Colorectal Cancer, and the American College of Radiology. CA Cancer J Clin. 2008;58(3):13060.

8. Schroy PC 3rd, Glick JT, Robinson PA, et al. Has the surge in media attention increased public awareness about colorectal cancer and screening? J Community Health. 2008;33(1):1-9.

9. Gimeno-Garcia AZ, Quintero E, Nicolas-Perez D, et al. Public awareness of colorectal cancer and screening in a Spanish population. Public Health. 2011;125(9):60915.

10. Senore C, Malila N, Minozzi S, et al. How to enhance physician and public acceptance and utilisation of colon cancer screening recommendations. Best Pract Res Clin
Gastroenterol. 2010;24(4):509-20.

11. Galal YS, Amin TT, Alarfaj AK, et al. Colon cancer among older Saudis: Awareness of risk factors and early signs, and perceived barriers to screening. Asian Pac J Cancer Prev. 2016;17:1837-46.

12. Al Eid ZM, Zahra'a Ibrahim AIRadhi ZA, AlTuraiki ESA, et al. Knowledge of colorectal cancer screening among men in AlAhsa, Saudi Arabia. 2017.

https://www.ijser.org/researchpaper/Knowledge-ofColorectal-Cancer-Screening-among-men-in-AlAhsaSaudi-Arabia.pdf

13. Almadi MA, Mosli MH, Bohlega MS, et al. Effect of public knowledge, attitudes, and behavior on willingness to undergo colorectal cancer screening using the health belief model. Saudi J Gastroenterol. 2015;21(2):71-77.

14. Zubaidi AM, AlSubaie NM, AlHumaid AA, et al. Public awareness of colorectal cancer in Saudi Arabia: A survey of 1070 participants in Riyadh. Saudi J Gastroenterol. 2015;21(2):78-83.

15. Al Wutayd O, Alamri F, Ali AM, et al. Colorectal cancer risk factors: a study of knowledge, attitude and practice among adults in Riyadh, Saudi Arabia. Cancer Res J. 2015;3(5):94-9.

16. Ali GY, Ali SI, Osaimi MBA, et al. Awareness and perception of colorectal cancer risk factors among Saudis in Eastern Province, Saudi Arabia. Int J Health Sci. 2015;3(2):2348-5728234.

17. Papanikolaou IS, Sioulas $A D$, Kalimeris $S$, et al. Awareness and attitudes of Greek medical students on colorectal cancer screening. World J Gastrointest Endosc. 2012;4(11):513-7.

18. Christou A, Thompson SC. Colorectal cancer screening knowledge, attitudes and behavioural intention among Indigenous Western Australians. BMC Public Health. 2012;12(1):528.

19. Bidouei $\mathrm{F}$, Abdolhosseini $\mathrm{S}$, Jafarzadeh $\mathrm{N}$, et al. Knowledge and perception toward colorectal cancer screening in east of Iran. Int J Health Policy Manag. 2014;3(1):11-5.

20. Aljumah AA, Aljebreen AM. Policy of screening for colorectal cancer in Saudi Arabia: A prospective analysis. Saudi J Gastroenterol. 2017;23(3):161-8.

21. Khayyat YM, Ibrahim EM. Public awareness of colon cancer screening among the general population: A study from the Western Region of Saudi Arabia. Qatar Med J. 2014:3.

22. Society AC. Cancer facts \& figures for African Americans: American Cancer Society; 1998. https://www.nrc.gov/docs/ml0716/ml071640135.pdf

23. Aljebreen AM. Clinico-pathological patterns of 
colorectal cancer in Saudi Arabia: younger with an advanced stage presentation. Saudi J Gastroenterol. 2007;13(2):84.

24. Sibiani A, Shaheen M, Fallatah HI, et al. Colorectal Cancer in Saudi Arabia King Abdul Aziz University Hospital: A Five Year Experience. J Med Med Sci. 2011;2(10):1126-30.

25. Fund WCR, Research AlfC. Food, nutrition, physical activity, and the prevention of cancer: a global perspective: Amer Inst for Cancer Research; 2007. https://www.wcrf.org/dietandcancer

26. Ries L, Melbert D, Krapcho $M$, et al. National Cancer Institute. SEER cancer statistics review, 1975-2005. Internet address: http://seer cancer gov/csr/1975_2004 (Based on November 2006 SEER data submission, posted to the SEER Web site, 2007)(Accessed 2018). 2007.

27. Aparna K. The knowledge, attitudes and practices approach: an evaluation of the barriers to colorectal cancer screening at Orange Blossom Family Health Johns Hopkins University School of Medicine, 2014. PCLPSite: Health Care Center for the Homeless, Orange Blossom Family Health, Orlando. 2014.

28. Puteh SEW, Khairudin SNA, Kabinchong $C$, et al. Relationship of Knowledge, Attitude, Practice (KAP) and Demographic factors with quality of life among urban colorectal cancer patients in Malaysia. Middle East J Cancer. 2014;5(1):31-40.

\section{ACKNOWLEDGEMENTS}

Data collectors: Hajar Alshmas, Norah Almarri, Somyyah Alnaimi

\section{PEER REVIEW}

Not commissioned. Externally peer reviewed.

\section{CONFLICTS OF INTEREST}

The authors declare that they have no competing interests.

\section{FUNDING}

None

\section{ETHICS COMMITTEE APPROVAL}

The study was approved by the Institutional Review Board (IRB) of Imam Abdulrahman bin Faisal University (IAU). Attached with the submission.

The study was administered to patients in a questionnaire style after obtaining verbal informed consent. 
Table 1: Sociodemographic data of the respondents, family and past history of colonoscopy and utilization of screening, knowledge of respondents about ranking of $\mathrm{CRC}$, age at risk, risk factors and awareness of screening programs

\begin{tabular}{|c|c|c|c|}
\hline \multirow{2}{*}{ Questions } & & \multicolumn{2}{|c|}{ All respondents ( $n=636$ ) } \\
\hline & & \multirow[t]{2}{*}{$\mathrm{n}$} & \multirow{2}{*}{$\begin{array}{l}\% \\
50.30 \%\end{array}$} \\
\hline \multirow{3}{*}{ Age } & 25 or less & & \\
\hline & $26-45$ & & $\%$ \\
\hline & 46 or more & & $\%$ \\
\hline \multirow{2}{*}{ Sex } & Male & 156 & $24.50 \%$ \\
\hline & Female & 480 & $75.50 \%$ \\
\hline \multirow{2}{*}{ Nationality } & Saudi & 619 & $97.30 \%$ \\
\hline & Non-Saudi & 17 & $2.70 \%$ \\
\hline \multirow{2}{*}{ Did you have family history } & Yes & 112 & $17.60 \%$ \\
\hline & No & 524 & $82.40 \%$ \\
\hline \multirow{4}{*}{ The degree of affected relative? } & First & 31 & $17.20 \%$ \\
\hline & Second & 28 & $15.60 \%$ \\
\hline & Third & 40 & $22.20 \%$ \\
\hline & Fourth & 81 & $45.00 \%$ \\
\hline \multirow{4}{*}{ At which age? } & Less than 20 & 3 & $3.00 \%$ \\
\hline & $20-39$ & 18 & $17.80 \%$ \\
\hline & $40-59$ & 47 & $46.50 \%$ \\
\hline & 60 or more & 33 & $32.70 \%$ \\
\hline \multirow{2}{*}{ Is anyone of your family had colonoscopy before? } & Yes & 330 & $51.90 \%$ \\
\hline & No & 306 & $48.10 \%$ \\
\hline \multirow{3}{*}{ Did you had colonoscopy before? } & Yes for screening & 14 & $2.20 \%$ \\
\hline & Yes for diagnosis & 51 & $8.00 \%$ \\
\hline & No & 571 & $89.80 \%$ \\
\hline \multirow{2}{*}{ Do you know how colonoscopy done? } & Yes & 219 & $34.40 \%$ \\
\hline & No & 417 & $65.60 \%$ \\
\hline \multirow{3}{*}{ Rank of CRC among male in SA } & First & 141 & $22.20 \%$ \\
\hline & Second & 288 & $45.30 \%$ \\
\hline & Third & 207 & $32.50 \%$ \\
\hline \multirow{3}{*}{ Rank of CRC among female in SA } & First & 81 & $12.70 \%$ \\
\hline & Second & 259 & $40.70 \%$ \\
\hline & Third & 296 & $46.50 \%$ \\
\hline \multirow{2}{*}{ Is there a screening program in SA for CRC? } & Yes & 316 & $49.70 \%$ \\
\hline & No & 320 & $50.30 \%$ \\
\hline \multirow{6}{*}{$\begin{array}{l}\text { Age of screening in healthy person? } \\
\text { (years) }\end{array}$} & 30 & 0 & $0.00 \%$ \\
\hline & 35 & 311 & $48.90 \%$ \\
\hline & 40 & 186 & $29.20 \%$ \\
\hline & 45 & 56 & $8.80 \%$ \\
\hline & 50 & 41 & $6.40 \%$ \\
\hline & No need for screening & 42 & $6.60 \%$ \\
\hline \multirow{5}{*}{$\begin{array}{l}\text { Age of screening in high risk person? } \\
\text { (years) }\end{array}$} & 30 & 457 & $71.90 \%$ \\
\hline & 35 & 104 & $16.40 \%$ \\
\hline & 40 & 65 & $10.20 \%$ \\
\hline & 45 & 10 & $1.60 \%$ \\
\hline & 50 & 0 & $0.00 \%$ \\
\hline
\end{tabular}




\begin{tabular}{|l|l|l|l|}
\hline \multirow{2}{*}{ Is PE examination enough to detection the CRC? } & Yes & 52 & $8.20 \%$ \\
\cline { 2 - 4 } & No & 584 & $91.80 \%$ \\
\hline \multirow{4}{*}{ Risk factors for CRC } & Obesity & 143 & $22.50 \%$ \\
\cline { 2 - 4 } & Smoking & 249 & $39.20 \%$ \\
\cline { 2 - 4 } & Family history & 356 & $56.00 \%$ \\
\cline { 2 - 4 } & Polyps & 228 & $35.80 \%$ \\
\cline { 2 - 4 } & IBD & 310 & $48.70 \%$ \\
\hline
\end{tabular}

n: number

Table 2: association between family and past history of colonoscopy and willingness to do screening

\begin{tabular}{|c|c|c|c|c|c|c|c|c|}
\hline \multirow{3}{*}{\multicolumn{2}{|c|}{ Variables }} & \multicolumn{6}{|c|}{ Are you willing to do screening? } & \multirow[t]{3}{*}{$p$-value } \\
\hline & & \multicolumn{2}{|c|}{$\begin{array}{l}\text { All respondents } \\
(n=636)\end{array}$} & \multicolumn{2}{|c|}{$\begin{array}{l}\text { Yes } \\
(n=486)\end{array}$} & \multicolumn{2}{|c|}{$\begin{array}{l}\text { No } \\
(n=150)\end{array}$} & \\
\hline & & $\mathrm{n}$ & $\%$ & $n$ & $\%$ & $n$ & $\%$ & \\
\hline \multirow{2}{*}{$\begin{array}{l}\text { Is anyone of your family } \\
\text { had colonoscopy before? }\end{array}$} & Yes & 330 & $51.9 \%$ & 267 & $54.9 \%$ & 63 & $42.0 \%$ & \multirow[t]{2}{*}{$0.006^{*}$} \\
\hline & No & 306 & $48.1 \%$ & 219 & $45.1 \%$ & 87 & $58.0 \%$ & \\
\hline \multirow{3}{*}{$\begin{array}{l}\text { Did you had colonoscopy } \\
\text { before? }\end{array}$} & Yes for screening & 14 & $2.2 \%$ & 13 & $2.7 \%$ & 1 & $0.7 \%$ & \multirow[t]{3}{*}{$0.016^{*}$} \\
\hline & Yes for diagnosis & 51 & $8.0 \%$ & 46 & $9.5 \%$ & 5 & $3.3 \%$ & \\
\hline & No & 571 & $89.8 \%$ & 427 & $87.9 \%$ & 144 & $96.0 \%$ & \\
\hline
\end{tabular}

